\title{
Article \\ Characterization of Biomarkers in Colorectal Cancer Liver Metastases as a Prognostic Tool
}

\author{
Sternschuss Michal ${ }^{1}{ }^{(D}$, Goshen-Lago Tal ${ }^{2}$, Perl Gali ${ }^{1,3}$, Goldenfeld Miki ${ }^{3} \mathbb{D}$, Brook Elana $^{4}$, Brenner Baroch $^{1,3}$, \\ Kashtan Hanoch ${ }^{3,5}$, Ben Aharon Irit ${ }^{2,6,+}$ and Haddad Riad 6,7,*,+ (D)
}

check for

updates

Citation: Michal, S.; Tal, G.-L.; Gali, P.; Miki, G.; Elana, B.; Baroch, B.; Hanoch, K.; Irit, B.A.; Riad, H. Characterization of Biomarkers in Colorectal Cancer Liver Metastases as a Prognostic Tool. J. Pers. Med. 2021, 11, 1059. https://doi.org/10.3390/ jpm11111059

Academic Editor: Soterios A. Kyrtopoulos

Received: 15 September 2021

Accepted: 19 October 2021

Published: 21 October 2021

Publisher's Note: MDPI stays neutral with regard to jurisdictional claims in published maps and institutional affiliations.

Copyright: (c) 2021 by the authors. Licensee MDPI, Basel, Switzerland. This article is an open access article distributed under the terms and conditions of the Creative Commons Attribution (CC BY) license (https:/ / creativecommons.org/licenses/by/ $4.0 /)$.
1 Davidoff Cancer Center, Rabin Medical Center, Division of Oncology, Petah Tikva 69978, Israel; avrahami.michal@gmail.com (S.M.); GaliP@clalit.org.il (P.G.); brennerb@clalit.org.il (B.B.)

2 Division of Oncology, Rambam Health Care Campus, Haifa 3109601, Israel;

T_goshenlago@rambam.health.gov.il (G.-L.T.); i_benaharon@rambam.health.gov.il (B.A.I.)

3 Sackler Faculty of Medicine, Tel Aviv University, Ramat Aviv, Tel Aviv 69978, Israel; goldenfeld@mail.tau.ac.il (G.M.); hkashtan@clalit.org.il (K.H.)

4 Rabin Medical Center, Department of Pathology, Petah Tikva 49100, Israel; elenabr1@clalit.org.il

5 Rabin Medical Center, Division of Surgery, Beilinson Campus, Petah Tikva 49100, Israel

6 Rappaport Faculty of Medicine, Technion, Haifa 3525428, Israel

7 Carmel Medical Center, Department of Surgery B, Haifa 3436212, Israel

* Correspondence: dr.riad.haddad@gmail.com

+ Equal Contribution.

Abstract: Background: Unfortunately, the majority of patients with colorectal cancer liver metastases (CRCLM) experience disease recurrence following hepatic surgery. The key challenge is therefore optimal patient selection, which currently relies on anatomical and clinical parameters. Exploring a potential molecular signature may be predictive for seeing a clinical benefit from CRCLM resection. Methods: Consecutive patients who underwent CRCLM resection at our medical center between 2006 and 2016 were divided into cohorts of "good prognosis" (GP) or "poor prognosis" (PP) based on the time interval between their resection and disease recurrence. Proteomic analysis was performed on the surgical specimen and correlation analysis was carried out with demographics and clinical outcomes. Results: Proteomic analysis revealed 99 differentially expressed proteins of which a third were associated with extracellular matrix (ECM) pathways as the matrix metalloproteinases (MMPs). Multivariate analysis yielded a statistically differential proteomic pattern between the cohort regardless of perioperative treatment. Conclusion: Our results indicate a different proteomic landscape in the cohort of patients who had a clinical benefit from CRCLM resection which appears to be correlated with ECM pathways. Further prospective studies are needed to define the role of ECM pathways in prognostics and patient selection for surgical procedures for CRCLM.

Keywords: colorectal cancer liver metastasis; hepatic surgery; prognosis; biomarkers; molecular signature

\section{Introduction}

Despite effective screening programs and comprehensive treatment, the mortality rate of colorectal cancer (CRC) remains high [1,2]. Approximately $25 \%$ of CRC patients are diagnosed with colorectal cancer liver metastases (CRCLM) and are defined as having synchronous CRCLM. Such synchronicity has been correlated with a poor prognosis [3].

Local therapies for CRCLM include surgical resection, stereotactic ablative body radiotherapy (SBRT), thermal ablation, selective internal radiotherapy (SIRT), bland or chemoembolization and hepatic arterial infusion [4]. For patients with limited disease, surgical resection remains the treatment of choice. Yet, the 5-year survival rates of patients treated surgically only reach to $30-50 \%$ and most patients experience a recurrence of the disease. The management of patients with CRCLM therefore remains challenging. The primary tumor location has been correlated with the prognosis after CRCLM resection. 
Namely, left-sided primary tumors have a significantly improved median overall survival though no superior recurrence free survival $[5,6]$. Another potential biomarker concerns the histopathologic growth patterns (HGP) of CRCLM; desmoplastic HGP are associated with improved survival compared with pushing and replacement HGP [7-9]. Nevertheless, although such clinical and pathological factors have been shown to be correlated with survival, patient selection criteria remain unclear. Since the majority of patients will experience recurrence, there is a need for superior surrogate prognostic and predictive biomarkers [10].

The introduction of predictive biomarkers such as KRAS, NRAS, BRAF and Microsatellite Instability (MSI) has provided the impetus to revisit the clinical approach for systemic treatment in metastatic CRC. Recently biomarkers, such as SMAD4 loss which is associated with a poor prognosis and a loss of immune infiltrate with an inverse response to treatment, have been identified yet not implemented into practical clinical considerations. Nevertheless, none have been shown to correlate with a better response to liver-directed therapies for CRCLM [11].

The recurrence of liver metastases following hepatic resections may derive from persistent residual microscopic disease. We therefore hypothesized that the interaction of hepatic stroma with macro and micro metastases and the activation of the immune system may play a key role in the eradication of residual disease (synergistic to systemic treatment). This may subsequently be translated into long-term remission following hepatectomy.

In this study we aimed to explore the molecular landscape of CRCLM and their adjacent hepatic stroma. This was in order to define a specific characteristic signature for patients who remain free of recurrence for more than 12 months after surgical resection of CRCLM compared to patients who experience early recurrence (within 12 months) after surgery. Accordingly, we aimed to evaluate potential biomarkers of the molecular signature that may be predictive for effective patient selection.

\section{Materials and Methods}

\subsection{Patients}

Consecutive patients with CRCLM who were treated at the department of surgery at Rabin Medical Center (RMC) between 2006 and 2016, and for whom formalin fixed frozen paraffin embedded (FFPE) surgical samples of liver metastases were available, were included in the study. Patients with extrahepatic metastases or insufficient clinical data were excluded. The remaining patients were dichotomized into "good prognosis" (GP) and "poor prognosis" (PP) cohorts based on their clinical and radiological evaluation of the interval to recurrence. The cutoff point of 12 months was chosen based on previous reports that found a correlation between the timing of recurrence and survival [12]. Budget constraints allowed the inclusion of 58 patients in this study; 29 patients in each cohort, and therefore required patient selection. In order to maximize the differentiation between the two cohorts, patients in the PP cohort were further dichotomized into very early recurrence ( $<6$ months) and early recurrence (6-12 months) groups. In the final analysis we included all patients with a very early recurrence in addition to randomly selected patients with early recurrence in the PP cohort and randomly selected patients in the GP cohort. Clinical data was retrieved from the RMC's Davidoff Cancer Center registry regarding patient demographics, histological traits of the tumor, cancer routine markers, chemotherapy and biological treatments, tumor location, disease recurrence, and survival. This study was approved by the medical center's ethics committee (0456-16RMC) and all procedures were performed in accordance with the institution's policy.

\subsection{Proteomic Analysis}

Proteomic analysis was performed at the Smoler Proteomics Center, Technion Institute, Israel. Five slides from each FFPE sample were micro-dissected to isolate and collect only the tumor cells of interest for analysis. The micro-dissected FFPE tumor tissue was then subjected to Liquid Tissue ${ }^{\circledR}$ processing to solubilize the tumor tissues. The patented Liquid 
Tissue ${ }^{\circledR}$ technology ensures that formalin cross-links are reversed and all the proteins in the tumor tissue are solubilized. Tissues were homogenized with Omni-Th homogenizer in Urea buffer containing: $8 \mathrm{M}$ Urea, $400 \mathrm{mM}$ Ammonium bicarbonate, and $10 \mathrm{mM}$ DTT. Homogenates were sonicated ( $5^{\prime}$, [10/10 on/off pulses], 90\% energy. Sonics Vibra-Cell (Sonics \& Materials, Inc., Newtown, CT, USA) and briefly centrifuged to pellet insoluble debris. The protein amount was estimated using Bradford readings. Then, 20 ug protein from each sample were reduced with DTT $\left(60^{\circ} \mathrm{C}\right.$ for $\left.30 \mathrm{~min}\right)$, modified with $40 \mathrm{mM}$ iodoacetamide in $100 \mathrm{mM}$ ammonium bicarbonate (in the dark, RT) and digested in $2 \mathrm{M}$ Urea, $100 \mathrm{mM}$ ammonium bicarbonate with modified trypsin (Promega), overnight at $37^{\circ} \mathrm{C}$ with a 1:50 enzyme-to-substrate ratio. An additional second digestion with trypsin was done for $4 \mathrm{~h}$ at $37^{\circ} \mathrm{C}$ with a 1:100 enzyme-to-substrate ratio. The tryptic peptides were desalted using C18 tips (Harvard) dried and re-suspended in $0.1 \%$ formic acid. The peptides were resolved by reverse-phase chromatography on $0.075 \times 300$-mm fused silica capillaries (J\&W) packed with Reprosil reversed phase material (Dr Maisch GmbH, Germany). The peptides were eluted with linear 180 minutes' gradient of 5 to $28 \%, 15$ min's gradient of 28 to $95 \%$, and $25 \mathrm{~min}$ at $95 \%$ acetonitrile with $0.1 \%$ formic acid in water at flow rates of $0.15 \mu \mathrm{L} / \mathrm{min}$. Mass spectrometry (MS) was performed by $\mathrm{Q}$ Exactive plus mass spectrometer (Thermo) in a positive mode using a repetitively full MS scan followed by High Collision Dissociation (HCD) of the 10 most dominant ions selected from the first MS scan. The mass spectrometry data was analyzed using the MaxQuant software 1.5.2.4. (www.maxquant.org) for peak picking identification and quantitation using the Andromeda search engine, searching against the human UniProt database with mass tolerance of $20 \mathrm{ppm}$ for the precursor masses and $20 \mathrm{ppm}$ for the fragment ions. Oxidation on methionine proline and lysine, and protein N-terminus acetylation were accepted as variable modifications and carbamidomethyl on cysteine was accepted as static modifications. Minimal peptide length was set to six amino acids and a maximum of two miscleavages was allowed. Peptide- and protein-level false discovery rates (FDRs) were filtered to $1 \%$ using the target-decoy strategy. Protein tables were filtered to eliminate identifications from the reverse database, and common contaminants and single peptide identifications. The data was quantified by label free analysis, using the same software based on extracted ion currents (XICs) of peptides, enabling the quantitation from each liquid chromotography/MS run for each peptide identified in any of experiments. The mass spectrometry proteomics data were sent to the ProteomeXchange Consortium and deposited in the PRIDE [13] partner repository with the dataset identifier PXD022613.

\subsection{Statistical Analysis}

For the proteomic analysis, the normal test was used on the fold change (using a log scale) to compare the expression of each protein between the GP and the PP groups. The $p$-values across all proteins were adjusted to control the FDR. The 0.05 level was used for significance. Multivariate logistic model was used to test the clinical effects on the probability for a one-year recurrence. Multivariate Cox proportional hazard regression was used to test the clinical effects on one-year recurrence free survival. Cox regression was also used to test the effect of each protein on this survival, adjusting the $p$-values across all proteins to control the FDR.

\section{Results}

Electronic medical records identified 259 patients with CRCLM who were treated at our medical center's surgery department during the study period, and for whom formalin fixed frozen paraffin embedded (FFPE) surgical samples of liver metastases were available, were identified through electronic medical records. Of these, 136 patients were excluded due to insufficient clinical data or extrahepatic metastases prior to liver resection. The remaining 123 patients were dichotomized into GP $(\mathrm{N}=68)$ and PP $(\mathrm{N}=55)$ cohorts. The median time to recurrence was 5.6 months in the PP cohort and 23.6 months in the GP cohort. 
In the final analysis, we included 29 randomly selected patients in the GP cohort, while the PP cohort consisted of all 19 patients with a very early recurrence and another 10 randomly selected patients with early recurrence. See Supplementary Materials Figure S1 for the patient inclusion flow-chart.

\subsection{Clinical Characteristics}

Patient characteristics are described in Table 1 . The PP cohort had a male predominance of $62 \%$ in contrast to $48 \%$ in the GP cohort, although this was not statistically significant. Family history of malignancy was found to be a factor for a poor prognosis from CRCLM. Such family history was found in 36\% of patients in the GP compared with $56 \%$ in the PP, where the hazard ratio for recurrence within 1 year from surgery in patients without family history was 0.3 [CI:(0.11,0.78), $p=0.0144]$ (Supplementary Materials Figure S2).

Table 1. Patients' Characteristics.

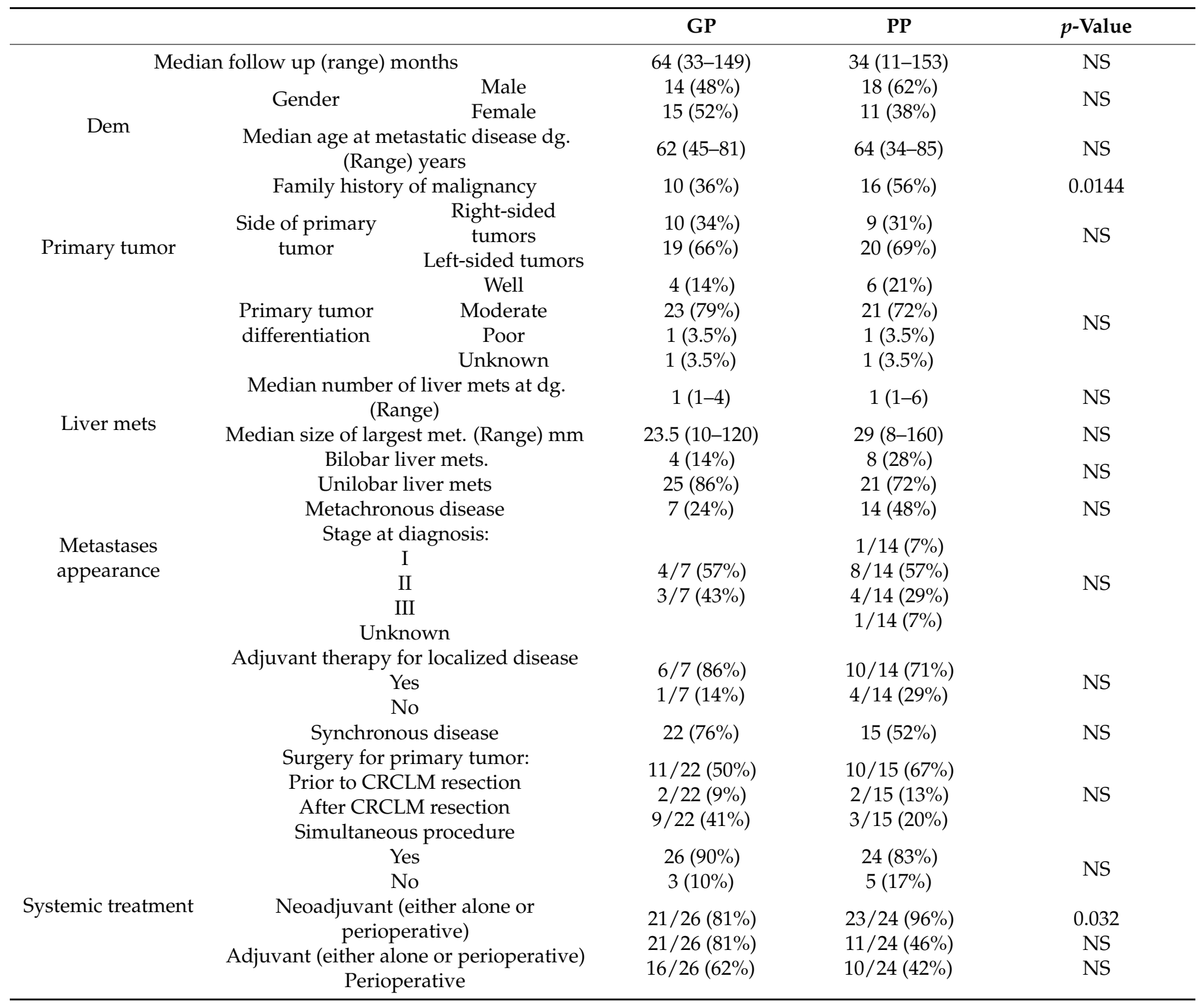


Table 1. Cont.

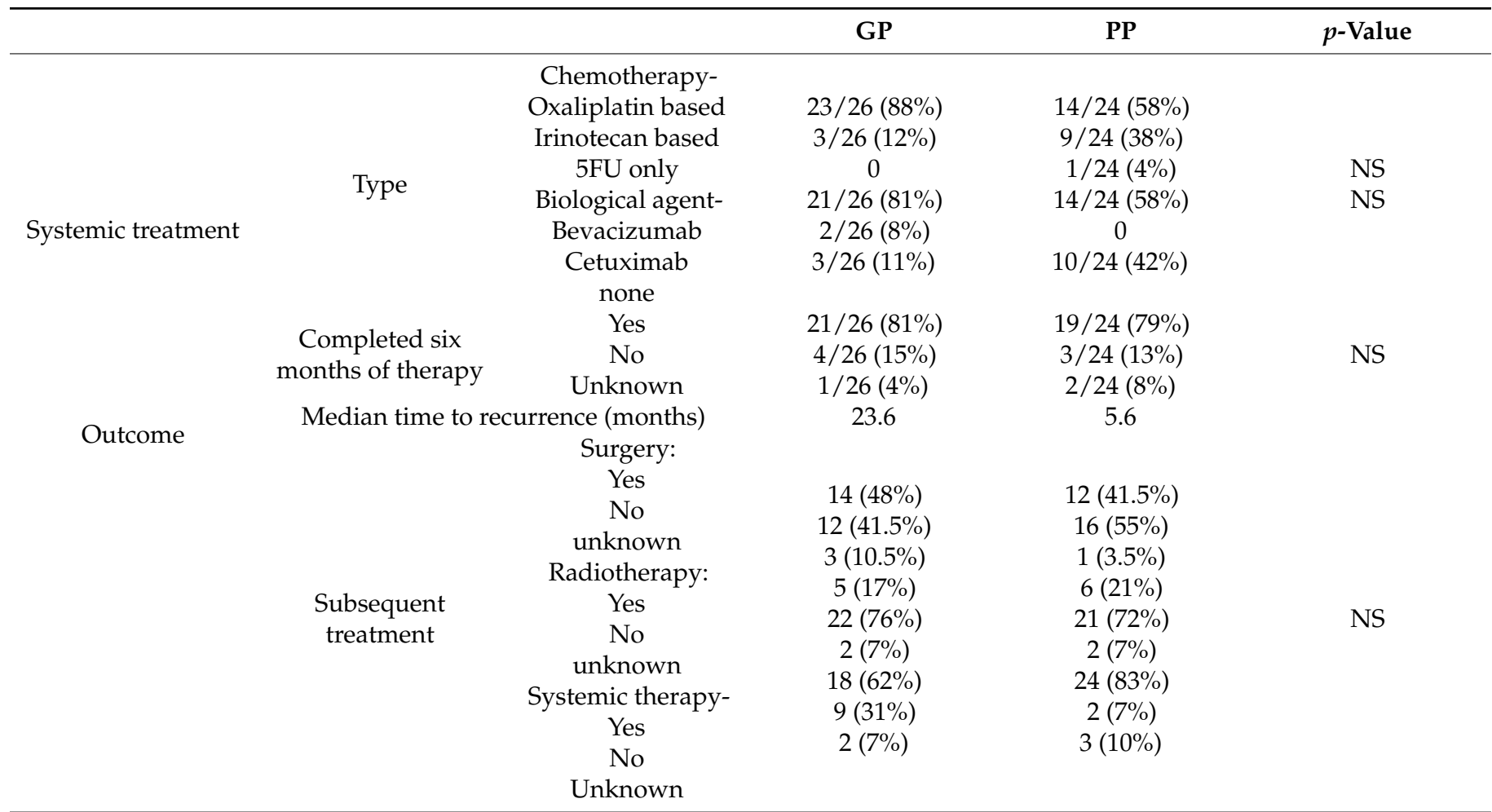

No.-Number, Pt.—Patient, Mets—Metastases, Dg—Diagnosis, NS—not significant, Dem-Demographics. GP—good prognosis, PP— poor prognosis.

The primary tumor location did not significantly differ between the two groups: $34 \%$ and $31 \%$ right-sided tumors in the GP and PP respectively. Although synchronicity is considered a poor prognostic factor, $76 \%$ of patients in the GP group had synchronous disease as compared with $52 \%$ in the PP, though this was not statistically significant.

The PP cohort had the same median number of hepatic metastases (1) as the GP, with a higher percentage of bi-lobar disease (28\% compared to $14 \%$ ), and slightly larger metastases (median $29 \mathrm{~mm}$ for the largest lesion compared with $23.5 \mathrm{~mm}$ ). These differences were not statistically significant. Supplementary Table S1 shows all the assessed prognostic factors.

The vast majority of our cohort received systemic chemotherapy (only $10 \%$ of the GP and $17 \%$ of the PP did not receive chemotherapy). Nevertheless, in the PP cohort only $35 \%$ received perioperative chemotherapy compared with 55\% in the GP cohort, though this did not reach statistical significance. The different treatment schedules of the two cohorts are described in Table 1. Interestingly, avoidance of neoadjuvant chemotherapy (either as part of a perioperative therapy or as neoadjuvant only therapy) was found to be significant in a multivariate analysis with a hazard ratio for recurrence within 1 year from surgery of 3.83 [CI:(1.12,13.06), $p$-value $=0.032$ ] (Supplementary Materials Figure S3).

The choice of treatment protocol was different between the cohorts with the majority of GP treated with oxaliplatin-based regimens (88\%) and bevacizumab $(81 \%)$, whereas in the PP only $58 \%$ received oxaliplatin-based chemotherapy (the rest were treated with irinotecan-based chemotherapy or 5FU alone) and were less likely to receive bevacizumab $(58 \%)$. These differences were not statistically significant.

\subsection{Proteomics}

Over 3700 proteins were identified using proteomic analysis. Expression levels were compared between the two cohorts. In 99 proteins, expression levels were significantly different between the two groups (Supplementary Materials Table S2). These proteins were further grouped to common pathways using the 'Gorilla' software. The protein expression 
is described in Table 2. Differences in proteomic profile appeared statistically significant in a multivariate analysis regardless of chemotherapy administration.

Table 2. Significant proteins according to proteomic analysis and their related pathways of expression-A normal test was used on the fold change (presented on a log scale) to compare the expression of each protein between the "good prognosis" and the "poor prognosis" groups. $p$-values across all proteins were adjusted to control the false discovery rate (FDR).

\begin{tabular}{|c|c|c|c|c|c|c|c|c|}
\hline Gene Name & Protein Name & $\begin{array}{l}\text { Ratio of Protein } \\
\text { Expression in Tumor } \\
\text { Samples of "Bad } \\
\text { Prognosis" vs. "Good } \\
\text { Prognosis" }\end{array}$ & $\begin{array}{l}\text { Fold Change } \\
\text { (Bad } \\
\text { Prognosis vs. } \\
\text { Good } \\
\text { Prognosis) }\end{array}$ & $\begin{array}{c}\text { FDR } \\
\text { Adjusted } \\
p \text {-Value }\end{array}$ & $\begin{array}{l}\text { Extracellular } \\
\text { Space }\end{array}$ & $\begin{array}{l}\text { Metallo } \\
\text { Peptidase } \\
\text { Activity }\end{array}$ & $\begin{array}{c}\text { DNA } \\
\text { Replication } \\
\text { and } \\
\text { Repair }\end{array}$ & $\begin{array}{l}\text { Immune } \\
\text { System }\end{array}$ \\
\hline AKR1B10 & $\begin{array}{l}\text { Aldo-keto reductase } \\
\text { family } 1 \text { member B10 }\end{array}$ & Down & 0.95 & $1.2 \times 10^{-4}$ & $\mathrm{~V}$ & & & \\
\hline APOB & $\begin{array}{l}\text { apolipoprotein } \mathrm{b} \\
\text { Complement } \mathrm{C} 1 \mathrm{r}\end{array}$ & Down & 0.97 & $2.0 \times 10^{-2}$ & $\mathrm{~V}$ & & & \\
\hline C1RL & $\begin{array}{l}\text { subcomponent-like } \\
\text { protein }\end{array}$ & Down & 0.97 & $4.7 \times 10^{-2}$ & $\mathrm{~V}$ & & & $\mathrm{~V}$ \\
\hline C5 & complement component 5 & Down & 0.96 & $1.1 \times 10^{-3}$ & $\mathrm{~V}$ & & & $\mathrm{~V}$ \\
\hline C8A & $\begin{array}{l}\text { Complement component } \\
\text { C8 alpha chain }\end{array}$ & Down & 0.95 & $3.2 \times 10^{-6}$ & $\mathrm{~V}$ & & & $\mathrm{~V}$ \\
\hline CD163 & Soluble CD163 & Down & 0.96 & $8.5 \times 10^{-4}$ & $\mathrm{~V}$ & & & $\mathrm{~V}$ \\
\hline CHGA & Chromogranin-A & Up & 1.05 & $5.6 \times 10^{-4}$ & $\mathrm{~V}$ & & & \\
\hline CMA1 & chymase 1 , mast cell & Down & 0.97 & $2.4 \times 10^{-2}$ & V & & & $\mathrm{V}$ \\
\hline DEFA5 & Defensin- 5 & Down & 0.94 & $1.9 \times 10^{-6}$ & $\mathrm{~V}$ & & & \\
\hline GCG & Glucagon & Down & 0.93 & $4.7 \times 10^{-9}$ & $\mathrm{~V}$ & & & \\
\hline GP2 & $\begin{array}{c}\text { Pancreatic secretory } \\
\text { granule membrane major } \\
\text { glycoprotein GP2 }\end{array}$ & Down & 0.96 & $7.2 \times 10^{-3}$ & $\mathrm{~V}$ & & & \\
\hline HLA-B & $\begin{array}{l}\text { HLA class I } \\
\text { histocompatibility antigen, } \\
\text { B-40 alpha chain }\end{array}$ & Down & 0.94 & $1.3 \times 10^{-6}$ & $\mathrm{~V}$ & & & $\mathrm{~V}$ \\
\hline HSD17B13 & $\begin{array}{l}\text { 17-beta-hydroxysteroid } \\
\text { dehydrogenase } 13\end{array}$ & Down & 0.96 & $4.1 \times 10^{-3}$ & $\mathrm{~V}$ & & & \\
\hline IGFBP2 & $\begin{array}{l}\text { Insulin-like growth } \\
\text { factor-binding protein } 2\end{array}$ & Up & 1.06 & $7.5 \times 10^{-5}$ & $\mathrm{~V}$ & & & \\
\hline IGLV3-10 & $\begin{array}{l}\text { immunoglobulin lambda } \\
\text { variable 3-10 }\end{array}$ & Up & 1.05 & $2.2 \times 10^{-4}$ & $\mathrm{~V}$ & & & \\
\hline KRT31 & keratin 31 & Down & 0.96 & $9.9 \times 10^{-3}$ & $\mathrm{~V}$ & & & \\
\hline KRT85 & keratin 85 & Down & 0.95 & $1.6 \times 10^{-4}$ & $\mathrm{~V}$ & & & \\
\hline LEFTY1 & $\begin{array}{l}\text { Left-right determination } \\
\text { factor } 1\end{array}$ & Up & 1.07 & $1.7 \times 10^{-7}$ & $\mathrm{~V}$ & & & \\
\hline LFNG & $\begin{array}{l}\text { Beta-1,3-N- } \\
\text { acetylglucosaminyltransferase } \\
\text { lunatic fringe }\end{array}$ & Down & 0.93 & $5.2 \times 10^{-10}$ & $\mathrm{~V}$ & & & \\
\hline LOXL1 & $\begin{array}{l}\text { Lysyl oxidase homolog } 1 \\
\text { Matrix-remodeling- }\end{array}$ & Down & 0.96 & $8.5 \times 10^{-4}$ & $\mathrm{~V}$ & & & \\
\hline MXRA5 & associated protein & Down & 0.96 & $7.4 \times 10^{-3}$ & $\mathrm{~V}$ & & & \\
\hline OLFM4 & Olfactomedin-4 & Down & 0.93 & $4.5 \times 10^{-11}$ & $\mathrm{~V}$ & & & \\
\hline OLFML1 & $\begin{array}{l}\text { Olfactomedin-like protein } \\
1\end{array}$ & Up & 1.05 & $2.5 \times 10^{-4}$ & $\mathrm{~V}$ & & & \\
\hline OSCAR & $\begin{array}{l}\text { Osteoclast-associated } \\
\text { immunoglobulin-like } \\
\text { receptor }\end{array}$ & Down & 0.97 & $3.8 \times 10^{-2}$ & $\mathrm{~V}$ & & & \\
\hline PROM1 & Prominin-1 & Down & 0.94 & $1.7 \times 10^{-6}$ & $\mathrm{~V}$ & & & \\
\hline PXDN & $\begin{array}{l}\text { Peroxidasin homolog } \\
\text { Tumor necrosis factor }\end{array}$ & Down & 0.95 & $1.8 \times 10^{-4}$ & $\mathrm{~V}$ & & & \\
\hline TNFSF13 & $\begin{array}{l}\text { ligand superfamily } \\
\text { member } 13\end{array}$ & Down & 0.97 & $3.0 \times 10^{-2}$ & $\mathrm{~V}$ & & & \\
\hline DPEP1 & Dipeptidase 1 & Up & 1.04 & $9.1 \times 10^{-3}$ & $\mathrm{~V}$ & $\mathrm{~V}$ & & \\
\hline MEP1A & $\begin{array}{l}\text { Metalloendopeptidase; } \\
\text { Meprin A subunit alpha }\end{array}$ & Down & 0.93 & $5.2 \times 10^{-10}$ & $\mathrm{~V}$ & $\mathrm{~V}$ & & \\
\hline MMP12 & $\begin{array}{l}\text { Macrophage } \\
\text { metalloelastase }\end{array}$ & Down & 0.95 & $2.7 \times 10^{-4}$ & $\mathrm{~V}$ & $\mathrm{~V}$ & & \\
\hline MMP7 & matrix metallopeptidase 7 & Up & 1.04 & $6.4 \times 10^{-3}$ & $\mathrm{~V}$ & $\mathrm{~V}$ & & \\
\hline ADAMDEC1 & adam-like, decysin 1 & Down & 0.96 & $4.1 \times 10^{-3}$ & $\mathrm{~V}$ & & & \\
\hline ENPEP & Glutamyl aminopeptidase & Down & 0.97 & $2.1 \times 10^{-2}$ & $\mathrm{~V}$ & & & \\
\hline METAP1 & $\begin{array}{l}\text { Methionine } \\
\text { aminopeptidase } 1\end{array}$ & Down & 0.96 & $3.2 \times 10^{-4}$ & $\mathrm{~V}$ & & & \\
\hline MSH2 & MutS homolog 2 & Up & 1.05 & $1.0 \times 10^{-4}$ & & & $\mathrm{~V}$ & \\
\hline MCM4 & $\begin{array}{l}\text { Minichromosome } \\
\text { maintenance } 4\end{array}$ & Up & 1.05 & $3.4 \times 10^{-4}$ & & & $\mathrm{~V}$ & \\
\hline
\end{tabular}

\subsubsection{ECM Pathway}

Thirty-four proteins which play a role in several pathways of the extracellular matrix reached statistical significance. A key player was the matrix metalloproteinases (MMPs). Several MMPs were upregulated in the PP: MMP7 by $4.37 \%(p=0.006)$ and Dehydropepti- 
dase 1 (DPEP1) by 4.25\% ( $p=0.009)$. Other MMPs were downregulated: MMP12 by $4.53 \%$ $(p=0.0003)$, Meprin-a (MEP1A) by $6.89 \%,(p<0.001)$, aminopeptidase A (APA or ENPEP) by $3.35 \%(p=0.021)$, and A disintegrin and metalloproteinase decysin 1 (ADAMDEC 1 ) by $3.87 \%(p=0.004)$. Other proteins involved in ECM related pathways that were downregulated in the PP compared with the GP include lysyl oxidase like 1 (LOXL1) by $4.26 \%$ $(p<0.001)$ and defensin alpha 5 paneth cell-specific (DEFA5) by $5.5 \%(p<0.001)$, while insulin-like growth factor binding protein 2 (IGFBP2) was upregulated by $5.56 \%(p<0.001)$.

\subsubsection{DNA Replication and Repair Pathways}

MSH2, a member of the mismatch repair (MMR) complex, was upregulated by $5.5 \%$ $(p<0.001)$ in the PP cohort compared with the GP; Minichromosome maintenance 4 (MCM4) was also upregulated by $5.16 \%(p<0.001)$. We could not detect any major differences in DNA repair pathways between the two groups.

\subsubsection{Immune Pathway}

Several components of the immune pathway were downregulated in the PP cohort compared with the GP, possibly reflecting the effect of the immune response in the two cohorts. The statistically significant downregulated proteins included Complement component 5 (C5) by 4.2\% ( $p=0.001)$; Complement C1r subcomponent-like protein (C1RL) by $3.05 \%(p=0.047)$; Complement component C8 alpha chain (C8A) by $5.4 \%(p<0.001)$; Soluble CD163 by $4.3 \%(p<0.001)$; chymase 1 expressed in mast cells by $3.3 \%(p=0.02)$, and major histocompatibility complex (HLA-B) by $5.6 \%(p<0.001)$.

Interestingly, Homebox protein CDX2, which has been associated with CRC aggressiveness, was not found to be significantly different between the two groups.

\section{Discussion}

We hypothesized that tumor unique characteristics and potential crosstalk with adjacent hepatic stroma may account for effective residual tumor eradication post resection of CRCLM regardless of perioperative systemic treatment. Comparing the baseline characteristics of the two cohorts (GP vs. PP) revealed no significant differences in demographics (sex and age). Furthermore, no correlation was found for habits (smoking and alcohol) and tumor characteristics (primary tumor location, KRAS status, number of liver metastases at diagnosis). Liver metastases synchronicity was also not associated with poorer prognosis. Patient characteristics were similar between the two cohorts implying the two groups were demographically balanced. Nevertheless, a lack of family history of malignancy was associated with a higher recurrence within one year compared with patients with a positive family history.

The impact of systemic treatment was analyzed and revealed differences between the two cohorts. Whereas perioperative treatment was indeed more prevalent in the GP cohort, in a multivariate analysis the differential gene expression pathway was significant regardless of perioperative treatment. This observation correlates to former evidence indicating that the addition of chemotherapy to surgical resection improves clinical outcome, however the optimal schedule in upfront resectable patients remains uncertain [14-16]. A lack of neoadjuvant treatment was also associated with a worse outcome. This observation may represent the clinical benefit of early treatment of micro-metastatic disease. The choice of chemotherapy regimen and biological agents differed between the cohorts with higher rates of irinotecan-based therapy in the PP and higher rates of bevacizumab in the GP, though no statistically significant conclusion could be drawn.

Evaluating the proteomic landscape of the two cohorts revealed 99 proteins that were differentially expressed, a third of which are associated with the ECM. However, we could not delineate a clear correlation between the ECM signature and clinical traits of the cohorts due to the limited sample size. We discuss below the current evidence regarding these proteins' role in invasiveness and metastases in CRC and other cancer types. 


\subsection{Matrix Metalloproteinase}

Currently published data describes a correlation between several proteins associated with the ECM and CRC aggressiveness. MMPs, a large family of zinc dependent endopeptidases, are known to play a crucial role in the degradation and remodeling of ECM and the processing of other bioactive molecules. As such, they were shown to contribute to tumor invasiveness and metastases in several cancer types including CRC, while changes in the expression of several members of this family of proteins were shown to be associated with increased mortality risk [17-20]. Despite encouraging results, the use of these biomarkers remains investigational. We did find a differential MMP signature between PP and GP. The proposed pathway displayed in PP is presented in Figure 1. Matrilysin, also known as MMP7, promotes cancer invasion in several processes including proteolytic cleavage of ECM proteins. While activation of other MMPs, including MMP2 and MMP9 overexpression and high levels of serum MMP7 levels, have been linked to CRC progression and decreased survival in advanced CRC $[18,20]$.

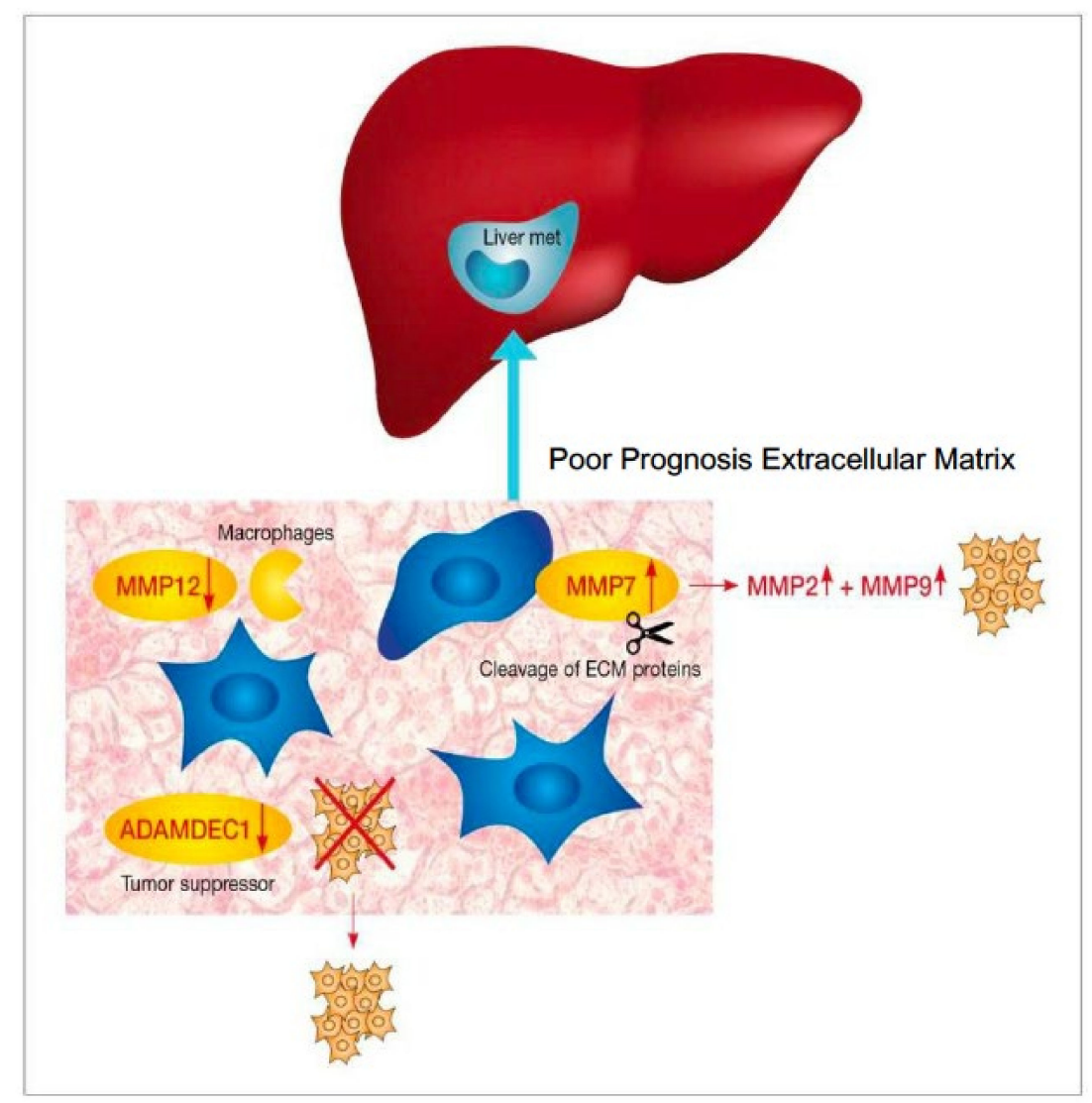

Figure 1. Scheme showing the "poor prognosis" microenvironment significant signature. In the "poor prognosis" microenvironment there is (i) Upregulation of MMP7 which promotes cancer invasion by proteolytic cleavage of ECM proteins and activation of cell proliferation through upregulation of MMP2 and MMP9 and (ii) Downregulation of the protective effect of MMP12 and the tumor suppressor, ADAMDEC1.

Our findings indicating higher levels of MMP7 in the PP group support previously published data, suggesting that MMP7 indeed plays a role in advanced metastatic CRC progression. Accordingly, serum MMP7 may be an appealing secreted biomarker that should be further studied in a prospective setting. Another member of the MMP family is MMP12, also known as Metalloelastase, which is a multi-substrate degrader predominantly expressed in macrophages. MMP12 has been shown to have a protective effect in CRC, where higher expression levels have been associated with primary tumors without hepatic metastases and better survival compared to CRCLM [21]. MMP12's effect on tumor 
progression may be mediated via its effect on the tumor vasculature. MMP12 is reciprocally expressed with vascular endothelial growth factor (VEGF) and is correlated with increased levels of angiostatin, an endogenous angiogenesis inhibitor [17,21]. Interestingly, Klupp et al. [22] found that higher serum levels of MMP12 were associated with a worse prognosis. The reason for these different observations isn't clear. Our results indicate decreased levels of MMP12 in the PP group suggesting the protective effect extends to the metastatic phase as well.

The ADAM family of proteins are involved in various biological events such as cell adhesion, cell fusion, cell migration, membrane protein shedding and proteolysis $[23,24]$. ADAMDEC1 is a known tumor suppressor gene that has been previously studied in CRC. ADAMDEC1 has been shown to be inversely expressed with the degree of disease aggressiveness, with a more prominent effect in patients without family history of CRC.

A potential aspect for further research is the correlation with HGP, as HGP subgroups are associated with a different ECM profile (e.g., collagen-rich stroma in desmoplastic growth patterns). Therefore, might relay on different proteolysis and spreading mechanisms [25], as well as different immune responses.

\subsection{Other ECM Pathways}

LOXL1 is a member of the LOX family of proteins, a copper-dependent amine oxidase that catalyzes the crosslinking of collagens and elastin in the ECM as well as being involved in intracellular and nuclear processes. Higher levels of LOX, and specifically nuclear expression, have been associated with metastases and poor prognosis [26]. In our study, LOXL1 was found to be downregulated in the PP cohort, contradicting previously published data. A possible explanation for this discrepancy may derive from our referral to total protein levels and not specifically nuclear location.

DNA replication and repair pathways MSH2 is a member of the mismatch repair proteins. Most published data regards the loss of its expression in the context of microsatellite instable (MSI) tumors and Lynch syndrome. However, data is scarce regarding isolated $\mathrm{MSH} 2$ expression or overexpression. Interestingly, we found overexpression of MSH2 in the PP group compared with the GP. It is not clear whether there is a correlation between this finding and the difference in family history between the cohorts. MCM4 belongs to the MCM protein complex which plays a role in the initiation of DNA replication and DNA unwinding [27]. Members of MCM complex are present in proliferating cells and overexpression has been described in several cancer types. A recently published CRC study described MCM4 as part of a novel four gene prognostic model [28]. Our results indicating overexpression in the PP cohort further supports the role of MCM4 as a marker for poor prognosis.

\subsection{Immune Pathways}

Understanding the role of the host immune system in tumor progression is an evolving research theme. Mounting evidence has correlated tumor infiltrating immune cells and the inflammatory response with clinical outcome [6]. In this study we found several significant differences in factors associated with the immune response. Complement 5 (C5) is a potent pro-inflammatory immune mediator that plays a role in innate immunity. Previous studies in cell lines found that c5 modulates tumor inflammation in CRC and has a pro-metastatic effect, while inhibition of the c5a receptor signaling severely impairs tumor metastasis [29]. Our results contradict these observations since we found decreased levels of C5 in the PP group.

Soluble CD163 is a monocyte-macrophage scavenger receptor and is regarded as a marker of macrophage activation. High serum levels of sCD163 have been described in several malignancies and have been shown to correlate with worse overall survival in gastric cancer patients [30]. Conversely, our cohort shows down regulation of sCD163 in the PP cohort, possibly reflecting lower levels of macrophage activation. 
Mast cells are tissue-resident immune cells that modulate the immune response. Their role in cancer progression is complex. There is evidence that they promote angiogenesis, proteolytic activity affecting ECM proteins, and cancer cell invasion and migration. Whereas other studies have suggested an antitumoral effect of mast cells. In our study, we found down regulation of chymase1 in the PP cohort, possibly indicating a pro-tumoral effect. Further research is warranted to define the role of the immune system in the tumor microenvironment in the context of hepatic metastases.

Our study has several limitations. The small sample size and the fact that we didn't perform corresponding transcriptome and genome analysis. Nevertheless, our results indicate a different proteomic landscape in the cohort of patients who had a clinical benefit from CRCLM resection which appears to be correlated with ECM pathway.

\section{Conclusions}

In the era of precision medicine, the clinical approach to CRCLM still relies on "traditional" factors including anatomical considerations and the number of metastases, there has been little consideration for molecular biomarkers. We found in this retrospective study that a unique signature of ECM proteins may serve as a ground for further large prospective research in order to validate the value of this proteomic signature and its role as a prognostic marker for CRCLM resection. Identifying potential biomarkers in the adjacent hepatic stroma in future prospective studies may allow for better selection of suitable candidates for CRCLM resection.

Supplementary Materials: The following are available online at https:/ / www.mdpi.com/article/ 10.3390/jpm11111059/s1, Figure S1: Patients inclusion flow-chart, Figure S2: KM Survival Curve according to patient's family history, Figure S3: KM Survival Curve according neoadjuvant treatment Table S1: List of assessed prognostic factors, Table S2: List of significantly expressed proteins.Please check if the individual contribution of each co-author has been stated.

Author Contributions: B.A.I. and H.R. developed and designed the study protocol. S.M., G.-L.T., H.R. and B.A.I. wrote the manuscript. S.M., G.-L.T., P.G., G.M. and B.E. carried out the data organization, samples collection and statistical analyses. B.B., K.H., B.A.I. and H.R. participated in recruiting patients contributed their data and discussed the results. All authors have read and agreed to the published version of the manuscript.

Funding: This research received no external funding.

Institutional Review Board Statement: The study was conducted according to the guidelines of the Declaration of Helsinki and approved by the Institutional Review Board of Rabin Medical Center (protocol code: 0456-16, date of approval: 9 August 2016).

Informed Consent Statement: Patient consent was waived due to being a retrospective study.

Data Availability Statement: The mass spectrometry proteomics data have been deposited to the ProteomeXchange Consortium via the PRIDE partner repository and is available with the dataset identifier PXD022613.

Acknowledgments: The authors thank Ruth Moont for reviewing and editing the manuscript.

Conflicts of Interest: The authors declare no conflict of interest.

\section{References}

1. Ferlay, J.; Soerjomataram, I.; Dikshit, R.; Eser, S.; Mathers, C.; Rebelo, M.; Parkin, D.M.; Forman, D.; Bray, F. Cancer incidence and mortality worldwide: Sources, methods and major patterns in GLOBOCAN 2012. Int. J. Cancer 2015, 136, E359-E386. [CrossRef]

2. Siegel, R.; Naishadham, D.; Jemal, A. Cancer statistics, 2013. CA Cancer J. Clin. 2013, 63, 11-30. [CrossRef] [PubMed]

3. Adam, R.; de Gramont, A.; Figueras, J.; Kokudo, N.; Kunstlinger, F.; Loyer, E.; Poston, G.; Rougier, P.; Rubbia-Brandt, L.; Sobrero, A.; et al. Managing synchronous liver metastases from colorectal cancer: A multidisciplinary international consensus. Cancer Treat. Rev. 2015, 41, 729-741. [CrossRef] [PubMed]

4. Van Cutsem, E.; Cervantes, A.; Adam, R.; Sobrero, A.; van Krieken, J.H.; Aderka, D.; Aguilar, E.A.; Bardelli, A.; Benson, A.; Bodoky, G.; et al. ESMO consensus guidelines for the management of patients with metastatic colorectal cancer. Ann. Oncol. 2016, 27, 1386-1422. [CrossRef] [PubMed] 
5. Creasy, J.M.; Sadot, E.; Koerkamp, B.G.; Chou, J.F.; Gonen, M.; Kemeny, N.E.; Saltz, L.B.; Balachandran, V.P.; Peter Kingham, T.; DeMatteo, R.P.; et al. The Impact of Primary Tumor Location on Long-Term Survival in Patients Undergoing Hepatic Resection for Metastatic Colon Cancer. Ann. Surg. Oncol. 2018, 25, 431-438. [CrossRef]

6. Donadon, M.; Lleo, A.; Di Tommaso, L.; Soldani, C.; Franceschini, B.; Roncalli, M.; Torzilli, G. The shifting paradigm of prognostic factors of colorectal liver metastases: From tumor-centered to host immune-centered factors. Front. Oncol. 2018, 8, 181. [CrossRef]

7. Van Dam, P.J.; Van Der Stok, E.P.; Teuwen, L.A.; Van Den Eynden, G.G.; Illemann, M.; Frentzas, S.; Majeed, A.W.; Eefsen, R.L.; Coebergh Van Den Braak, R.R.J.; Lazaris, A.; et al. International consensus guidelines for scoring the histopathological growth patterns of liver metastasis. Br. J. Cancer 2017, 117, 1427-1441. [CrossRef]

8. Buisman, F.E.; van der Stok, E.P.; Galjart, B.; Vermeulen, P.B.; Balachandran, V.P.; van den Braak, R.R.J.C.; Creasy, J.M.; Höppener, D.J.; Jarnagin, W.R.; Kingham, T.P.; et al. Histopathological growth patterns as biomarker for adjuvant systemic chemotherapy in patients with resected colorectal liver metastases. Clin. Exp. Metastasis 2020, 37, 593-605. [CrossRef]

9. Han, Y.; Chai, F.; Wei, J.; Yue, Y.; Cheng, J.; Gu, D.; Zhang, Y.; Tong, T.; Sheng, W.; Hong, N.; et al. Identification of Predominant Histopathological Growth Patterns of Colorectal Liver Metastasis by Multi-Habitat and Multi-Sequence Based Radiomics Analysis. Front. Oncol. 2020, 10, 1363. [CrossRef]

10. Kanas, G.P.; Taylor, A.; Primrose, J.N.; Langeberg, W.J.; Kelsh, M.A.; Mowat, F.S.; Alexander, D.D.; Choti, M.A.; Poston, G. Survival after liver resection in metastatic colorectal cancer: Review and meta-analysis of prognostic factors. Clin. Epidemiol. 2012, 4, 283-301. [CrossRef] [PubMed]

11. Wasserman, I.; Lee, L.H.; Ogino, S.; Marco, M.R.; Wu, C.; Chen, X.; Datta, J.; Sadot, E.; Szeglin, B.; Guillem, J.G.; et al. Smad4 loss in colorectal cancer patients correlates with recurrence, loss of immune infiltrate, and chemoresistance. Clin. Cancer Res. 2019, 25, 1948-1956. [CrossRef] [PubMed]

12. Takahashi, S.; Konishi, M.; Nakagohri, T.; Gotohda, N.; Saito, N.; Kinoshita, T. Short time to recurrence after hepatic resection correlates with poor prognosis in colorectal hepatic metastasis. Jpn. J. Clin. Oncol. 2006, 36, 368-375. [CrossRef]

13. Perez-Riverol, Y.; Csordas, A.; Bai, J.; Bernal-Llinares, M.; Hewapathirana, S.; Kundu, D.J.; Inuganti, A.; Griss, J.; Mayer, G.; Eisenacher, M.; et al. The PRIDE database and related tools and resources in 2019: Improving support for quantification data. Nucleic Acids Res. 2019, 47, D442-D450. [CrossRef]

14. Araujo, R.L.C.; Gönen, M.; Herman, P. Chemotherapy for Patients with Colorectal Liver Metastases Who Underwent Curative Resection Improves Long-Term Outcomes: Systematic Review and Meta-analysis. Ann. Surg. Oncol. 2015, 22, $3070-3078$. [CrossRef]

15. Ciliberto, D.; Prati, U.; Roveda, L.; Barbieri, V.; Staropoli, N.; Abbruzzese, A.; Caraglia, M.; Di Maio, M.; Flotta, D.; Tassone, P.; et al. Role of systemic chemotherapy in the management of resected or resectable colorectal liver metastases: A systematic review and meta-analysis of randomized controlled trials. Oncol. Rep. 2012, 27, 1849-1856. [CrossRef] [PubMed]

16. Ratti, F.; Fuks, D.; Cipriani, F.; Gayet, B.; Aldrighetti, L. Timing of Perioperative Chemotherapy Does Not Influence LongTerm Outcome of Patients Undergoing Combined Laparoscopic Colorectal and Liver Resection in Selected Upfront Resectable Synchronous Liver Metastases. World J. Surg. 2019, 43, 3110-3119. [CrossRef]

17. Said, A.H.; Raufman, J.P.; Xie, G. The role of matrix metalloproteinases in colorectal cancer. Cancers 2014, 6, 366-375. [CrossRef]

18. Koskensalo, S.; Louhimo, J.; Nordling, S.; Hagström, J.; Haglund, C. MMP-7 as a prognostic marker in colorectal cancer. Tumor Biol. 2011, 32, 259-264. [CrossRef] [PubMed]

19. Vočka, M.; Langer, D.; Fryba, V.; Petrtyl, J.; Hanus, T.; Kalousova, M.; Zima, T.; Petruzelka, L. Serum levels of TIMP-1 and MMP-7 as potential biomarkers in patients with metastatic colorectal cancer. Int. J. Biol. Markers 2019, 34, 292-301. [CrossRef]

20. Chen, H.; Hu, Y.; Xiang, W.; Cai, Y.; Wang, Z.; Xiao, Q.; Liu, Y.; Li, Q.; Ding, K. Prognostic significance of matrix metalloproteinase 7 immunohistochemical expression in colorectal cancer: A meta-analysis. Int. J. Clin. Exp. Med. 2015, 8, 3281-3290.

21. Asano, T.; Tada, M.; Cheng, S.; Takemoto, N.; Kuramae, T.; Abe, M.; Takahashi, O.; Miyamoto, M.; Hamada, J.I.; Moriuchi, T.; et al. Prognostic Values of Matrix Metalloproteinase Family Expression in Human Colorectal Carcinoma. J. Surg. Res. 2008, 146, 32-42. [CrossRef] [PubMed]

22. Klupp, F.; Neumann, L.; Kahlert, C.; Diers, J.; Halama, N.; Franz, C.; Schmidt, T.; Koch, M.; Weitz, J.; Schneider, M.; et al. Serum MMP7, MMP10 and MMP12 level as negative prognostic markers in colon cancer patients. BMC Cancer 2016, 16, 494. [CrossRef] [PubMed]

23. Macartney-Coxson, D.P.; Hood, K.A.; Shi, H.; Ward, T.; Wiles, A.; O'Connor, R.; Hall, D.A.; Lea, R.A.; Royds, J.A.; Stubbs, R.S.; et al. Metastatic susceptibility locus, an $8 \mathrm{p}$ hot-spot for tumour progression disrupted in colorectal liver metastases: 13 candidate genes examined at the DNA, mRNA and protein level. BMC Cancer 2008, 8, 187. [CrossRef]

24. Mochizuki, S.; Okada, Y. ADAMs in cancer cell proliferation and progression. Cancer Sci. 2007, 98, 621-628. [CrossRef]

25. Van Den Eynden, G.G.; Majeed, A.W.; Illemann, M.; Vermeulen, P.B.; Bird, N.C.; Høyer-Hansen, G.; Eefsen, R.L.; Reynolds, A.R.; Brodt, P. The multifaceted role of the microenvironment in liver metastasis: Biology and clinical implications. Cancer Res. 2013, 73, 2031-2043. [CrossRef] [PubMed]

26. Liu, Y.; Wang, G.; Liang, Z.; Mei, Z.; Wu, T.; Cui, A.; Liu, C.; Cui, L. Lysyl oxidase: A colorectal cancer biomarker of lung and hepatic metastasis. Thorac. Cancer 2018, 9, 785-793. [CrossRef]

27. Forsburg, S.L. Eukaryotic MCM Proteins: Beyond Replication Initiation. Microbiol. Mol. Biol. Rev. 2004, 68, 109-131. [CrossRef] 
28. Ahluwalia, P.; Mondal, A.K.; Bloomer, C.; Fulzele, S.; Jones, K.; Ananth, S.; Gahlay, G.K.; Heneidi, S.; Rojiani, A.M.; Kota, V.; et al. Identification and Clinical Validation of a Novel 4 Gene-Signature with Prognostic Utility in Colorectal Cancer. Int. J. Mol. Sci. 2019, 20, 3818. [CrossRef]

29. Piao, C.; Cai, L.; Qiu, S.; Jia, L.; Song, W.; Du, J. Complement 5a enhances hepatic metastases of colon cancer via monocyte chemoattractant protein-1-mediated inflammatory cell infiltration. J. Biol. Chem. 2015, 290, 10667-10676. [CrossRef]

30. Ding, D.; Song, Y.; Yao, Y.; Zhang, S. Preoperative serum macrophage activated biomarkers soluble mannose receptor (SMR) and soluble haemoglobin scavenger receptor (SCD163), as novel markers for the diagnosis and prognosis of gastric cancer. Oncol. Lett. 2017, 14, 2982-2990. [CrossRef] 